\title{
Study on Vacuum Suction Casting for TiAl-Based Alloys
}

\section{Su Yanqing, Ye Xicong, Guo Jingjie, Fu Hengzhi}

\author{
Harbin Institute of Technology, Harbin 150001, China
}

\begin{abstract}
A novel type of foundry method for TiAl-based alloy is presented in the present paper. The filling processes of Ti-47Al alloy sheet and blade have been studied via numerical simulation. The investigation results indicate that the filling fraction is enhanced by the increase of filling velocity and graphite throat diameter. The graphite throat diameter is the main parameter for the backward filling location in the process of vacuum suction casting. With the increase of mould temperature, the solid fraction is reduced. The alloy solidification begins from bottom to top. The TiAl sheet and the blade are produced by this method. The grain size of the sheet is in the range from $10 \mu \mathrm{m}$ to $40 \mu \mathrm{m}$. There is no obvious shrinkage cavity.
\end{abstract}

Key words: vacuum suction casting; numerical simulation; graphite throat diameter; solid fraction; filling fraction

TiAl based alloys are considered as promising structural materials for applications in the fields of aerospace vehicle, energy and automotive industry ${ }^{[1-5]}$. Their advantages involve low density, high specific yield strength, high specific stiffness, good oxidation resistance, and good creep resistance up to high temperatures etc. But the alloys have low room temperature plastic property, low deformation limit and bad cold-forming property, so the improper properties restrict their cold workability. The barriers to practical applications of TiAl based alloys include not only their inherent properties but also the high-cost of processing. Casting is the most economical way to produce TiAl based alloy components. Different casting methods such as conventional sand casting ${ }^{[6]}$, die casting ${ }^{[7]}$, low pressure casting ${ }^{[8]}$, centrifugal casting ${ }^{[9]}$, shell mould casting $^{[10]}$, extrusion casting ${ }^{[11]}$ and etc., are used, and the investment casting offer an economical production route ${ }^{[12,13]}$. However, there are some problems in the above casting methods, such as grain size and reaction layer.

This work aim is made to develop a novel type of casting method called permanent mould suction casting for TiAl based alloys. The filling process is accomplished under vacuum condition, so the oxidation and pore can be avoided. The solidification velocity of TiAl based alloy is fast, so the misrun and cold shut may appear, especially in the process of complex thin wall component. The suction casting can overcome their deficiencies, because the mould is filled with the molten metal under gravity and extra gas pressures. The filling process has been simulated with PROCAST software. A blade and sheet of TiAl based alloy have been also produced by this method.

\section{Suction CastingTechn ology}

The most important issue of thin-walled TiAl based alloy component is the casting defect of misrun. In order to avoid this issue, extra filling force is required, and in this work the extra force was gas pressure. The suction casting alloy ingots were fabricated by vacuum-arc melting technique in a melting chamber as shown in Fig.1. The melting chamber was filled with high purity argon, and the pressure could be up to 0.07 $\mathrm{MPa}$ as filling force. The suction chamber was vacuumized by a mechanical pump. The extra force of the suction casting was provided by the differential pressure between the melting chamber and the suction chamber. Thus, suction casting was successful in preventing casting defects by means of suction force. Oxide and oxygen contents were also reduced because of the vacuumized suction chamber. A permanent mould was designed for suction casting.

\section{Simulation and Analysis in Process of Suction Casting}

Filling velocity, graphite throat diameter and pouring temperature are the main influencing factors in the filling process of suction casting. In this paper, the effects of filling velocity,

Received date: October 08, 2008

Foundation item: NSCF(50271020, 50771041); Program of Excellent Team in Harbin Institute of Technology

Biography: Su Yanqing, Ph. D., Professor, School of Materials Science and Engineering, Harbin Institute of Technology, Harbin 150001, P. R. China, Tel: 0086-451-86417395, E-mail: suyq@hit.edu.cn 
graphite throat diameter and pouring temperature on the sheet and blade filling process were simulated by the PROCAST software.

\subsection{Model}

Fig.2 shows the three-dimensional geometry model of the sheet and the blade. The sheet casting with $2 \mathrm{~mm}$ in thickness, $60 \mathrm{~mm}$ in length and $20 \mathrm{~mm}$ in width was selected, and the blade casting with $50 \mathrm{~mm}$ in length, $20 \mathrm{~mm}$ in width and $2 \mathrm{~mm}$ in thickness, and with $1.6 \mathrm{~mm}$ thickness in ledge. The mould is made of steel.

\subsection{The effect of technological parameter on the filling of sheet and blade}

In order to evaluate the influence of filling velocity on filling process, the filling velocity was selected as $457,610,762$ and $914 \mathrm{~mm} / \mathrm{s}$, respectively. The graphite throat diameter was $2 \mathrm{~mm}$, and the filling temperature was $1590{ }^{\circ} \mathrm{C}$. The mould temperature was $20^{\circ} \mathrm{C}$.

Fig.3a shows the influence of filling velocity on filling fraction. From the simulation results, it can be seen that the filling fractions of four filling velocities are less than $100 \%$ because of small graphite throat diameter. However, the increase of filling velocity can improve the filling fraction obviously; the excessive filling velocity will lead to a backward filling, resulting in cast defects.

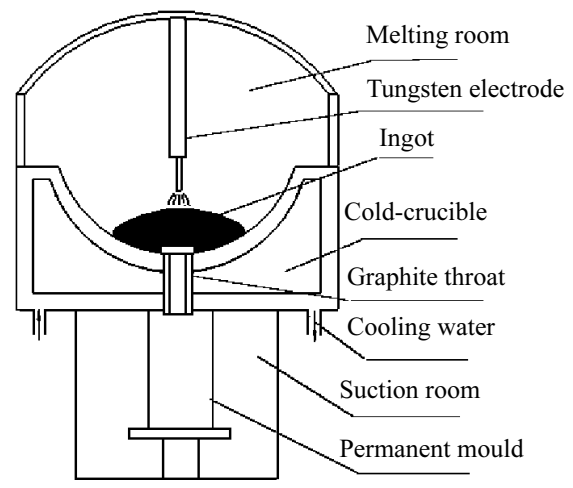

Fig.1 Schematic of suction casting

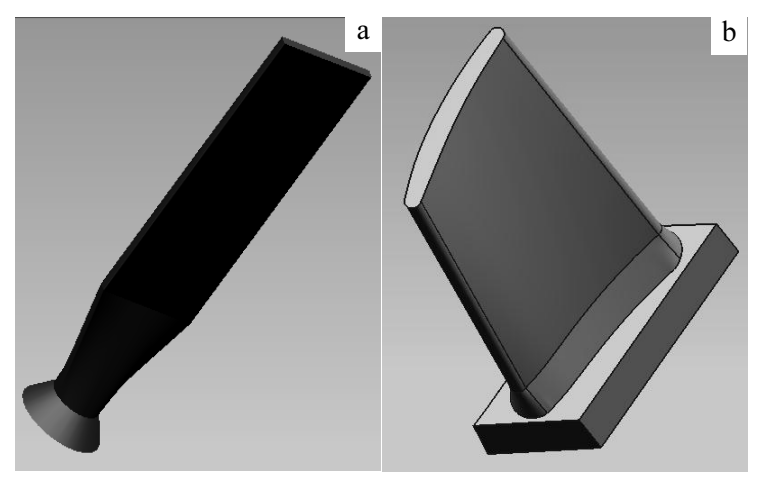

Fig.2 Geometry models of castings: (a) sheet and (b) blade
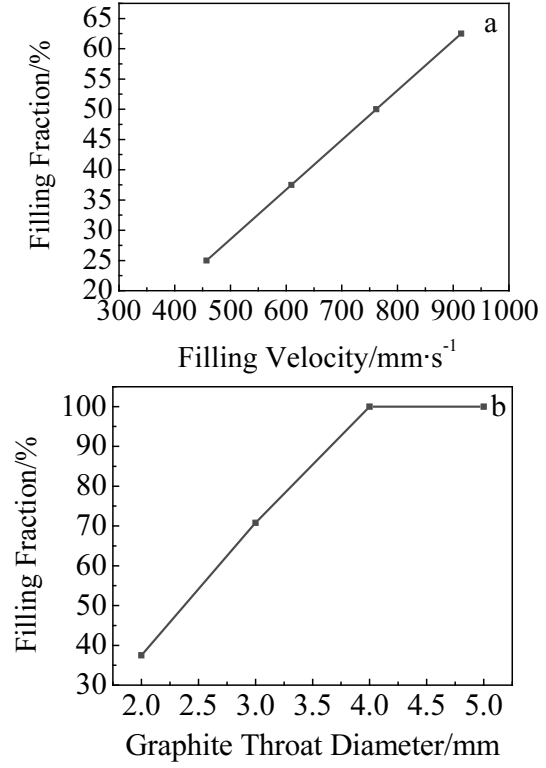

Fig.3 Influence of the filling velocity (a) and graphite throat diameter (b) on the filling fraction

The surface tension is related to the graphite throat diameter. With the decrease of the graphite throat diameter, the capillary surface tension increases, and the filling resistance increases. Additionally, the small graphite throat diameter will lead to less filling amount of molten metal under the same filling velocity. These unfavourable factors lead to half-baked filling. If the graphite throat diameter is too big, the just molten metal is directly sucked into cavity and the temperature of the molten metal is non-uniform. In order to evaluate the influence of graphite throat diameter on filling process, the graphite throat diameter was selected as $2,3,4$ and $5 \mathrm{~mm}$ respectively. The filling temperature was $1620{ }^{\circ} \mathrm{C}$. The cast mould temperature was $20^{\circ} \mathrm{C}$, and filling velocity was 610 $\mathrm{mm} / \mathrm{s}$. Fig. $3 \mathrm{~b}$ shows, with the increase of graphite throat diameter, the filling fraction increases too. When the graphite throat diameter is $4 \mathrm{~mm}$, the filling fraction is $100 \%$.

In order to evaluate the influence of backward filling on sheet casting, the graphite throat diameter was selected as 2, 3, 4 and $5 \mathrm{~mm}$, respectively. The filling temperature was 1620 ${ }^{\circ} \mathrm{C}$. The cast mould temperature was $20^{\circ} \mathrm{C}$, and filling velocity was $610 \mathrm{~mm} / \mathrm{s}$. The results are shown in Fig.4a. It is clear to see, with the increase of graphite throat diameter, the location of backward filling changed from bottom to top. When the graphite throat diameter was $4 \mathrm{~mm}$, the location of backward filling was removed from sheet casting.

The effect of graphite throat diameter and filling velocity on blade filling, and the effect of cast mould temperature on filling fraction are similar to TiAl based sheet. Therefore, the location of backward filling is the main object. For evaluating the influence of the graphite throat diameter on blade casting, the graphite throat diameters were selected as 2,3 and $4 \mathrm{~mm}$, 
respectively. The filling temperature was $1620{ }^{\circ} \mathrm{C}$. The cast mould temperature was $20^{\circ} \mathrm{C}$, and filling velocity was 457 $\mathrm{mm} / \mathrm{s}$. The results are shown in Fig. $4 \mathrm{~b}$. When graphite throat diameter was $3 \mathrm{~mm}$, the location of backward filling appeared in bottom, and the filling was unsymmetrical. When graphite throat diameter was $4 \mathrm{~mm}$, the location emerged in the connection between the blade and its rabbet.

For evaluating the influence of mould temperature on filling fraction, the temperature was selected as 20,40,60, 80 and $100{ }^{\circ} \mathrm{C}$, respectively. The graphite throat diameter was $4 \mathrm{~mm}$, and the filling temperature was $1590^{\circ} \mathrm{C}$. The filling velocity was $610 \mathrm{~mm} / \mathrm{s}$. Local solidification fraction is the ratio of solidified molten metal to molten metal. In general, when the local solidification fraction reaches $20 \%$, the filling process will stop. The $20 \%$ local solidification fraction was observed in the filling process of suction casting. The solidification sequence was from bottom to top, as shown in Fig.5, which would not influence the filling process. With the increase of mould temperature, the proportion of solidified metal decreases.

\section{Experimental Results}

According to simulation results, we selected the graphite throat with diameter of $4 \mathrm{~mm}$, and the filling temperature was $1620^{\circ} \mathrm{C}$, the cast mould temperature was $20^{\circ} \mathrm{C}$, and filling velocity was $457 \mathrm{~mm} / \mathrm{s}$ for experiment. Fig. 6 shows the TiAl based alloy castings of sheet and blade.

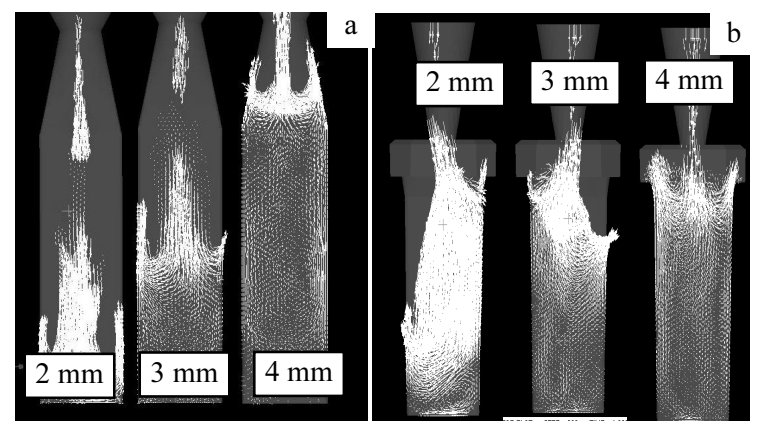

Fig.4 Effect of graphite throat diameter on backward filling of sheet(a) and blade (b)

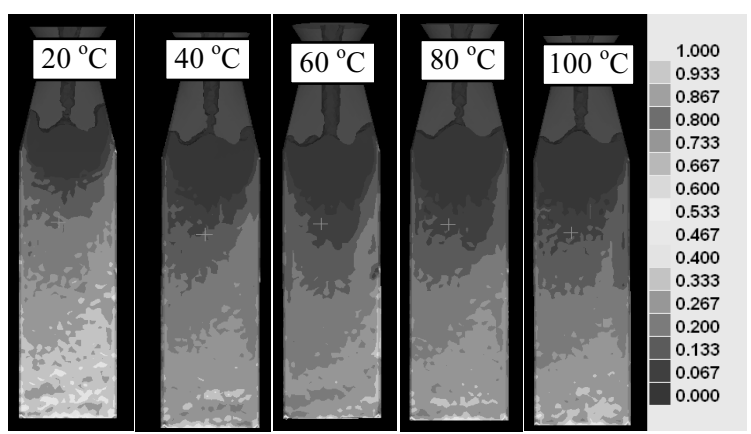

Fig.5 Relationship between casting mould temperature and solid fraction

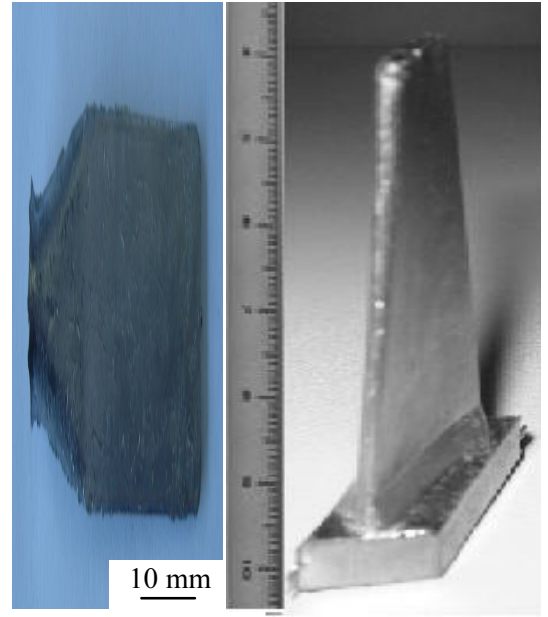

Fig.6 Ti-47Al-2W-0.5Si sheet and Ti-47Al-5Nb-0.5B blade

Fig.7 is the BSE micrograph of Ti-47Al-2W-0.5Si. This alloy has compact and fine grain structure, and the grain size is in the range from 10 to $40 \mu \mathrm{m}$. There was no obvious shrinkage cavity, but only small shrinkage porosity was observed. Fig. 8 is the energy spectrum analysis of gray base, and no iron element was detected. Therefore, there are no reaction between molten TiAl alloy and the mould.

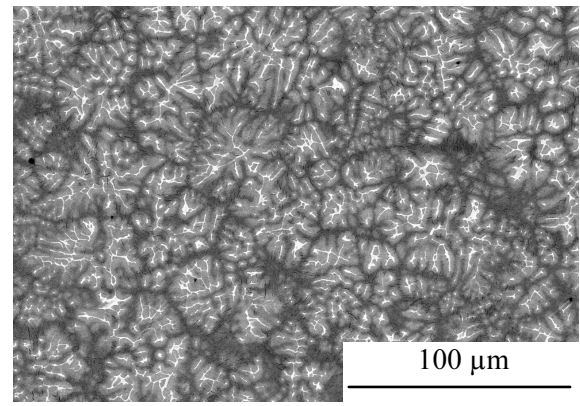

Fig.7 BSE micrograph of Ti-47Al-2W-0.5Si

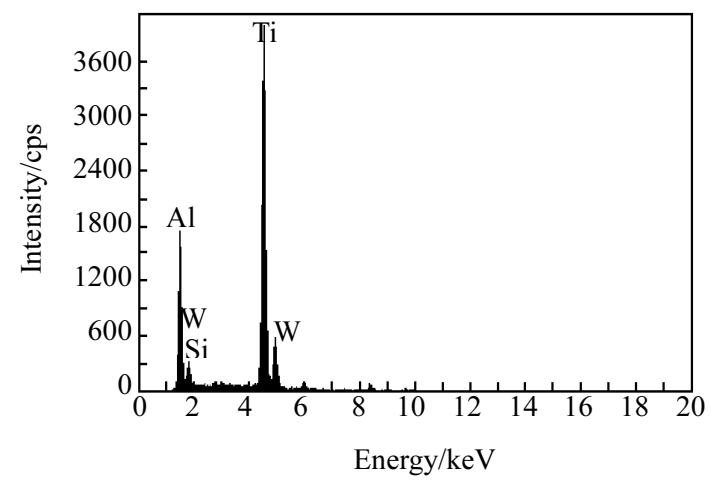

Fig.8 Energy spectrum analysis chart of Ti-47Al-2W-0.5Si 


\section{Conclusions}

1) With the increase of graphite throat diameter and filling velocity, the filling ability of TiAl based alloy molten is improved under suction casting. The proportion of the local solidification fraction decreases with the increase of the cast mould temperature. The TiAl based alloy molten metal is solidified from bottom to top.

2) The blade and the sheet of TiAl based alloy can be produced by suction casting. No reaction takes place between active moltenmetal and the steel permanent mould.

3) This alloy has compact and fine grain structure, and the grain size is in the range from 10 to $40 \mu \mathrm{m}$. There is no obvious shrinkage cavity.

\section{References}

1 Noda T, Okabe M, Isobe S et al. Materials Science and Engineering[J], 1995, A192/193: 774

2 Beddoes J, Seo D Y, Saari H. Scripta Material[J], 2005, 52: 745

3 Lapin J. Scripta Material[J], 2004, 50: 261
4 Hao Shiming(郝士明). Materials Review(材料进展)[J], 1993, 7(3): 11

5 Qu Cuifen(屈翠芬). Rare Metal Materials and Engineering(稀 有金属材料与工程)[J], 1991, 20(6): 19

6 Johnson D R, Inui H, Yamaguchi M. Intermetallics[J], 1998, 6: 647

7 Rawers J C, Wrzesinski W. Scripta Metallurgica et Materialia[J], 1990, 24: 1985

8 Zhang B, Maijer D M, Cockcroft S L. Materials Science and Engineering: $A[\mathrm{~J}], 2007,464: 295$

9 Sheng Wenbin. Transactions of Nonferrous Metals Society of China[J], 2006(16): 719

10 Yang R, Cui Y Y, Dong L M et al. Journal of Materials Processing Technology[J], 2003, 135: 179

11 Vijayaram T R, Sulaiman S, Hamouda A M S et al. Journal of Materials Processing Technology[J], 2006, 178: 34

12 Alain Lasalmonie. Intermetallics[J], 2006, 14: 1123

13 Noda T. Intermetallics[J], 1998, 6: 709

\title{
TiAI 基合金金属型真空吸铸成形方法研究
}

\author{
苏彦庆, 叶喜葱, 郭景杰, 傅恒志 \\ (哈尔滨工业大学, 黑龙江 哈尔滨 150001)
}

\begin{abstract}
摘 要: 提出了一种钛铝基合金金属型真空吸铸成形新方法, 并通过数值模拟研究了 TiAl 基合金薄板、叶片的充型规律。研究表明, 在真空吸铸过程中, 充型速度和石墨吸口直径的增加, 有利于充型分数的提高, 另外石墨吸口直径与反向充填出现的位置密切相关。在 凝固过程中，合金从下而上逐层凝固，但随着铸型温度的增加，凝固了的合金在金属液中所占的比例减少。以数值模拟结果指导试验， 得到质量良好的 $\mathrm{TiAl}$ 基合金薄板和叶片铸件。

关键词：真空吸铸；数值模拟；石墨吸口直径；凝固分数；充型分数
\end{abstract}

作者简介: 苏彦庆, 男, 1969 年生, 博士, 教授, 哈尔滨工业大学材料科学与工程学院, 黑龙江 哈尔滨 150001, 电话: 0451-86413795, E-mail: suyq@hit.edu.cn 